\title{
Sulfonylurea Receptor Expression in Rat Brain: Effect of Chronic Hypoxia during Development
}

\author{
YING XIA, DAVID EISENMAN. AND GABRIEL G. HADDAD \\ Department of Pediatrics (Section of Respiratory Medicine, Laboratory of Respiratery Nentobiology) /Y.X., D.E.. \\ G.G.H.J and Interdepartmental Nentroscience Program /G.G.H.J. Yale University. School of Medicine. \\ New Haren. Connecticut (06.510
}

\begin{abstract}
ABSTRACI. Sulfonylurea receptors are believed to be related to ATP-sensitive potassium channels and play a key role during hypoxia/ischemia in the CNS. Our previous work has shown that these receptors in rat brainstem neurons are more important in the adult rat than in the newborn during hypoxia. In the present study, we studied the time course of postnatal development of sulfonylurea receptors in detail and the effect of chronic hypoxia on receptor density in newborn pups and adult rats exposed to hypoxia either as fetuses or as $\mathbf{9 0 - d - o l d ~ r a t s ~ u s i n g ~}$ receptor binding and autoradiography. Our current results show that sulfonylurea receptor density $l$ ) was very low at birth and developed fast within the first 2 postnatal wk and then gradually reached adult levels and 2) continued to increase in the cortex and cerebellum but decreased in the brainstem with little or no change in other areas after postnatal wk 5 . Chronic hypoxia $I$ ) decreased body weight, brain size, and brain protein concentration and 2 ) increased sulfonylurea receptor density in utero but had much less of an effect in the adult. From these data, we conclude that sulfonylurea receptors develop mostly in the first $2 \mathrm{wk}$ postnatally and chronic hypoxia increases sulfonylurea receptor expression in utero in spite of the fact that overall protein decreases. (Pediatr Res 34: ó34-641, 1993)
\end{abstract}

\section{Abbreviations}

\section{$P$, postnatal day}

P0H, hypoxic newborn rat (hypoxia from E11-12 to P0)

$K_{\text {ATP, }}$ ATP-sensitive potassium

HEPES, $N$-2-hydroxyethylpiperazine- $N^{\prime}$-2-ethanesulfonic acid

$\mathrm{FiO}_{2}$, fractional oxygen concentration

We have recently shown that during graded hypoxic stress, adult rat neurons from the brainstem, hippocampus, and neocortex depolarize in a major way after different time periods (1$5)$. Newborn neurons, on the other hand, hardly depolarize over similar periods of time of $\mathrm{O}_{2}$ deprivation $(3,4)$. The reasons for this major difference are not known but may be related by and large to better maintenance of ionic homeostasis in the young (4).

Additional recent studies in vivo and in vitro from our laboratory and those of others have shown that during hypoxia/ anoxia, extracellular $\mathrm{K}^{+}$increases due to loss of intracellular $\mathrm{K}^{+}$

Received December 15. 1992: accepted June 17, 1993.

Correspondence: Gabriel G. Haddad. M.D., Department of Pediatrics, Section of Respiratory Medicine. Yale University. FITKIN Bldg. Rm. 5-506, 333 Cedar St.. New Haven. CT 06510.

Supported by Grants HD 15736, 28940, and HL 39924 from the National Institutes of Health. in the brain with much greater extent in the adult than in the newborn. The loss of intracellular $\mathrm{K}^{+}$is mainly through certain specific $\mathrm{K}^{+}$channels and can be blocked by glibenclamide, a potent sulfonylurea ligand. These results can imply that $\mathrm{K}_{\mathrm{ATP}}$ channels play an important role in preventing or dampening the depolarization during brain hypoxia because evidence suggests that sulfonylurea blocks $\mathrm{K}_{\mathrm{ATP}}$ channels $(6,7)$. We previously argued that this type of mechanism, i.e. activation of these channels, is an adaptive cellular response that may provide neurons with a means for delaying injury or surviving periods of insufficient oxygenation or energy supply (4). Because $I$ ) chronic hypoxia is often seen in the clinical setting, whether in the adult or young human, and 2) $\mathrm{K}_{\mathrm{ATP}}$ channels are clearly linked to conditions affecting intermediary metabolism and adaptation to stress $(4,8-10)$, we asked whether chronic hypoxia influences the expression of these channels in the CNS at a number of anatomical levels. It is also clear that because the expression of these channels is dependent on age, it is imperative to normalize to chronologic age, prenatally or postnatally. As a first step, we studied sulfonylurea receptor density using receptor binding techniques and autoradiography in the adult hypoxic rats and in newborn pups that were exposed to chronic hypoxia before birth. We hypothesized that both hypoxia and ontogeny are stimuli for expression of these receptors.

\section{MATERIALS AND METHODS}

Materials. ${ }^{3} \mathrm{H}$-glibenclamide $(54.7 \mathrm{Ci} / \mathrm{mmol})$ was purchased from New England Nuclear (Boston, MA). Unlabeled glibenclamide was purchased from Sigma Chemical Co. (St. Louis. MO). HEPES and other compounds were purchased from Aldrich (Milwaukee, WI) or Sigma Chemical Co.

Animals. Sprague-Dawley rats at P0 (within $12 \mathrm{~h}$ after birth), P14, P21, P90, and P120 and pregnant rats on the 11 th to 12 th $\mathrm{d}$ of gestation were used. For autoradiographic quantitation of sulfonylurea receptor binding, each group contained four rats.

Indluction of hypoxia. Because we were interested in imposing a significant stress on these rats, we exposed rats to a relatively long period of hypoxia. We exposed fetuses at an early stage, starting at 11-12 d of conceptional age. For adult rats, exposure was for 1 mo. Thus, pregnant rats and $\mathrm{P} 90$ rats were placed in an isobaric chamber at an $\mathrm{FiO}_{2}$ of $8-10 \%$. Pups whose mothers were exposed to hypoxia were killed within $12 \mathrm{~h}$ after birth $(\mathrm{P} 0 \mathrm{H})$. Adult hypoxic rats were killed at $120 \mathrm{~d}$ of age $(\mathrm{P} 120 \mathrm{H})$. Control litters were kept in a normal environment and killed at the appropriate age (P0C, P120C). Animals were killed during methoxyflurane inhalation anesthesia. Before the rats were killed, body weight and hematocrit were measured.

Tissuc preparation. The brains were rapidly removed into cold Ringer's solution and then frozen in isopentane in a dry ice/ methanol bath. The frozen brains were stored in $\mathrm{a}-80^{\circ} \mathrm{C}$ freezer. Using a Hacker-Bright cryostat (Hacker Instruments, Inc., Fairfield. NJ), $10-\mu \mathrm{m}$ thick coronal sections were cut at $-20^{\circ} \mathrm{C}$. For 
determining brain size, measuring protein, and counting bound radioactivity, four levels of the brain were sectioned. The first level ( $\mathrm{Ll}$ ) was around $3.3 \mathrm{~mm}$ posterior to bregma according to the rat brain atlas of Paxinos and Watson (11), containing frontoparietal cortex, rostral hippocampus, thalamus, and hypothalamus (Fig. la). The second level (L2) was around $5.8 \mathrm{~mm}$ posterior to bregma, containing striate cortex, caudal hippocampus, and substantia nigra (Fig. 1b). The third level (L3) was around $9.8 \mathrm{~mm}$ posterior to bregma, containing cerebellum and pons (Fig. 1c). The fourth level (L4) was around obex level, containing hypoglossal and solitary tract nuclei (Fig. 1d). The sections were thaw-mounted onto precleaned and gelatin-coated microscope slides and stored at $-80^{\circ} \mathrm{C}$.

Measurement of brain size. Using a computer image processing system, surface areas of brain autoradiographic images were measured and pixel values were used as an index for brain size because all brains were treated in the same way.

Measurement of brain weight. The rat brain was cut at the level of $2 \mathrm{~mm}$ below obex and then the whole brain was dipped in liquid nitrogen and weighed.

Comparison of protein amount. Protein amount in brain sections was assayed using Bradford's method (12). Because all sections were of the same thickness $(10 \mu \mathrm{m})$, the relative amount of protein in a given brain section was obtained by measuring protein in a particular brain section and determining the area in the adjacent section. In brief, after quantitating pixel number in sections by a computerized image processing system, protein content ( $\mu \mathrm{g}$ protein/section) was normalized to $\mu \mathrm{g}$ protein/pixel unit and the difference between control and hypoxia groups was converted to percent change (with control values as $100 \%$ ). This method allowed us to determine whether differences existed among various brain levels using small amounts of tissue.

Receptor binding. The methods have been described in our previous publication (13). In brief, the slide-mounted sections were gradually brought up to room temperature and dried in cool air for $10 \mathrm{~min}$. To deplete the tissue of putative endogenous ligands, the thawed and dried sections were preincubated for 10 min at $20^{\circ} \mathrm{C}$ in $20 \mathrm{mM}$ HEPES- $\mathrm{NaOH}$ buffer $(\mathrm{pH} \mathrm{7.4)}$ and then were blown dry with a stream of cool air at room temperature for $10 \mathrm{~min}$. The sections were incubated for $60 \mathrm{~min}$ at $4^{\circ} \mathrm{C}$ with $2.5 \mathrm{nM}{ }^{3} \mathrm{H}$-glibenclamide in $20 \mathrm{mM}$ HEPES-NaOH buffer $(\mathrm{pH}$ 7.4). Nonspecific binding was estimated from adjacent sections in parallel incubations in the presence of $1 \mu \mathrm{M}$ unlabeled glibenclamide. To wash nonspecific binding, incubated slides were consecutively rinsed in seven different jars containing $500 \mathrm{~mL}$ of cold buffer (20 s each) and finally dipped in a jar containing $500 \mathrm{~mL}$ of cold distilled water. The binding studies were carried out blind.

Radioactivity counting. Incubated brain sections on each slide were completely wiped off with filter paper and placed into a counting vial. Ten $\mathrm{mL}$ of scintillation liquid (OPTI-FLUOR, Packard, Meriden, CT) were added to each vial. The radioactivity was counted in a Packard beta-counter. After subtracting nonspecific binding and measuring the protein amount of the adjacent section, the radioactivity in a given section was normalized to $\mathrm{fmol} / \mathrm{mg}$ protein.

Autoradiography: The rinsed slides were dried rapidly under a stream of cold and dry air and stored in a desiccant and pressurereduced jar at $4^{\circ} \mathrm{C}$ for $3 \mathrm{~d}$. Subsequently, slides were placed in exposure cassettes along with tritium standards and covered with a tritium-sensitive film $\left(\left[{ }^{3} \mathrm{H}\right]\right.$-Ultrofilm, Cambridge Instruments $\mathrm{GmbH}$, Nussloch, Germany) and stored at $4^{\circ} \mathrm{C}$ for exposure. After 8 wk, the films were developed in Kodak D-19 for 5 min at $19^{\circ} \mathrm{C}$ and fixed.

Image analysis. After developing each film, all brain sections were stained with cresyl violet for histologic verification of anatomical structures, which were identified by reference to the rat brain atlas (11). The autoradiographic images were quantitated with a computerized imaging system. After correction for the contribution of nonspecific binding and background film density,
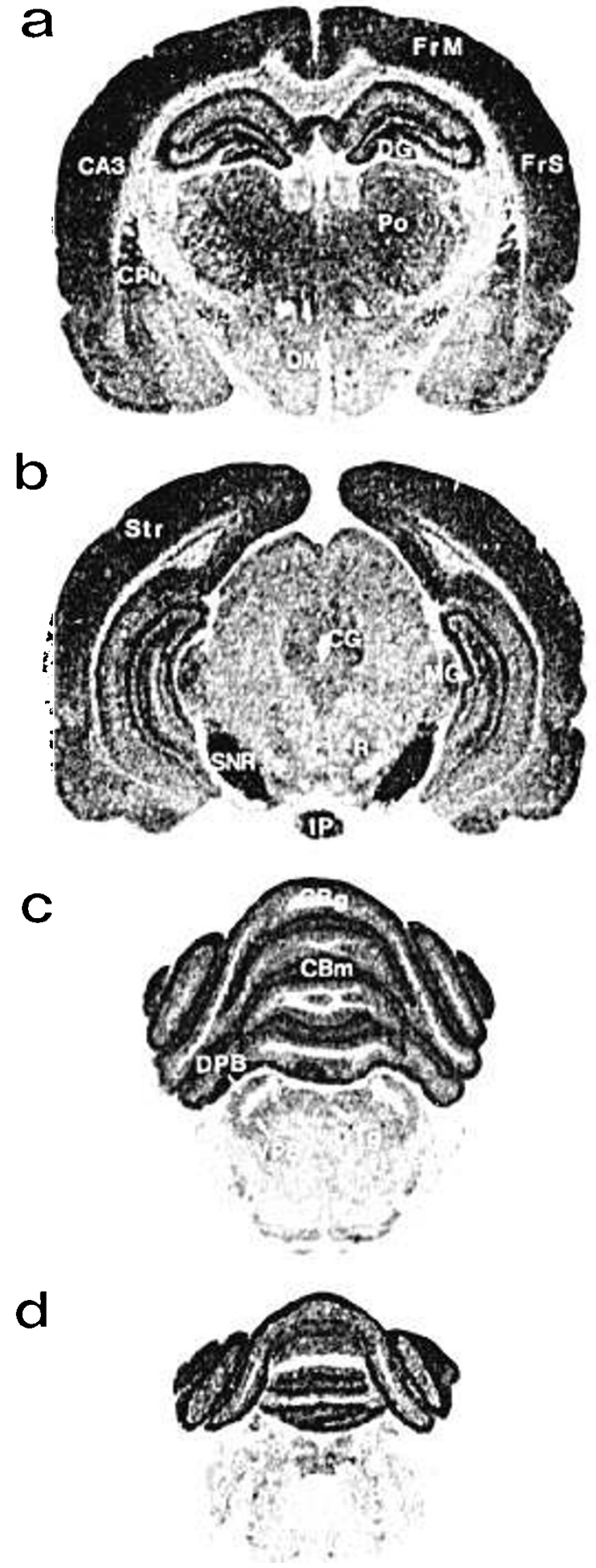

Fig. I. Glibenclamide binding at four brain levels in the adult rat CNS. Note that the darker the color the higher the binding density is. All four pictures have the same density scales. $a$. Brain level $1 ; b$, brain level 2; 2 , brain level 3 ; and $d$, brain level 4. C $A 3$, field CA3 of Ammon's horn: $(\mathrm{Bg}$. granular layer of cerebellum: ( $\mathrm{Bm}$. molecular layer of cerchellum: $(' G$, central gray matter: $(P u$. caudate putamen: $D(i$. dentate gyrus: $D . M$. dorsomedial hypothalamic nucleus: $D P B$. dorsal parabrachial nucleus: DTg. dorsal tegmental nucleus: Fr.W. frontoparietal cortex. motor area: IFS, frontoparietal cortex, somatosensory area: $I I Y$, hypoglossal nucleus: $I O$, inferior olive: $I P$, interpeduncular nucleus: $M G$, medial geniculate nucleus; $P$ ), posterior thalamic nuclear group; $R$, red nucleus: $S_{S} N R$, substantia nigra, reticular part: $S t r$, striate cortex: and $I ' P B$, ventral parabrachial nucleus. 
XIA $E T . A L$.

Table 1. Ontogeny' of ${ }^{3} H$-glibenclamide binding sites in rat CNS*

\begin{tabular}{|c|c|c|c|c|c|}
\hline Areas & $\mathrm{P} 0$ & $\mathrm{P} 14$ & $\mathrm{P} 21$ & P35 & $\mathrm{P} 120$ \\
\hline \multicolumn{6}{|l|}{ Cortex } \\
\hline Frontoparietal cortex, motor area & $2.4 \pm 0.5$ & $25.8 \pm 3.4$ & $32.9 \pm 1.6$ & $36.1 \pm 2.4$ & $43.4 \pm 2.9$ \\
\hline Frontoparietal cortex, somatosensory area & $2.3 \pm 0.6$ & $22.3 \pm 2.6$ & $25.6 \pm 1.5$ & $31.6 \pm 2.5$ & $40.1 \pm 4.5$ \\
\hline Striate cortex & $3.7 \pm 0.3$ & $17.4 \pm 1.4$ & $25.4 \pm 4.8$ & $31.5 \pm 4.8$ & $34.2 \pm 1.0$ \\
\hline Retrosplenial cortex & & $15.9 \pm 1.6$ & $24.6 \pm 4.0$ & $32.2 \pm 5.6$ & $33.7 \pm 4.1$ \\
\hline Posterior cingulate cortex & $1.8 \pm 0.4$ & $25.2 \pm 2.4$ & $31.8 \pm 1.6$ & $34.5 \pm 3.2$ & $36.9 \pm 5.0$ \\
\hline Temporal cortex, auditory area & & $13.5 \pm 1.5$ & $18.2 \pm 4.9$ & $22.5 \pm 3.2$ & $25.0 \pm 0.5$ \\
\hline Primary olfactory nucleus & & $24.1 \pm 2.3$ & $19.1 \pm 2.6$ & $20.2 \pm 2.1$ & $20.4 \pm 1.3$ \\
\hline Entorhinal cortex & & $17.0 \pm 1.1$ & $12.7 \pm 3.4$ & $17.5 \pm 2.5$ & $18.4 \pm 3.7$ \\
\hline \multicolumn{6}{|l|}{ Basal ganglia } \\
\hline Globus pallidus & $4.0 \pm 0.4$ & $38.1 \pm 1.2$ & $42.9 \pm 4.0$ & $37.4 \pm 2.7$ & $32.4 \pm 2.0$ \\
\hline Caudate putamen & $3.8 \pm 0.5$ & $26.8 \pm 4.3$ & $25.8 \pm 1.0$ & $27.6 \pm 1.1$ & $25.0 \pm 4.0$ \\
\hline \multicolumn{6}{|l|}{ Amygdala } \\
\hline Basolateral amygdaloid nucleus & $3.7 \pm 0.3$ & $19.3 \pm 1.3$ & $19.3 \pm 4.2$ & $21.6 \pm 0.9$ & $19.8 \pm 3.1$ \\
\hline Medial amygdaloid nucleus & & $10.7 \pm 3.8$ & $14.9 \pm 2.4$ & $14.9 \pm 1.7$ & $11.5 \pm 2.2$ \\
\hline Posteromedial cortical amygdaloid nucleus & $2.4 \pm 0.5$ & $13.9 \pm 0.6$ & $18.0 \pm 5.8$ & $19.2 \pm 4.6$ & $14.2 \pm 1.1$ \\
\hline \multicolumn{6}{|l|}{ Hippocampus } \\
\hline Field CAl of Ammon's horn & $3.9 \pm 0.3$ & $22.6 \pm 1.6$ & $21.3 \pm 2.0$ & $25.1 \pm 1.8$ & $23.6 \pm 6.1$ \\
\hline Field CA3 of Ammon's horn & $4.6 \pm 1.0$ & $36.5 \pm 4.7$ & $43.0 \pm 1.5$ & $41.0 \pm 3.4$ & $41.1 \pm 2.5$ \\
\hline Dentate gyrus & & $24.3 \pm 1.3$ & $26.1 \pm 4.5$ & $29.2 \pm 1.4$ & $34.4 \pm 3.0$ \\
\hline \multicolumn{6}{|l|}{ Thalamus } \\
\hline $\begin{array}{l}\text { Ventroposterior thalamic nucleus, medial } \\
\text { part }\end{array}$ & $5.4 \pm 1.2$ & $23.3 \pm 1.1$ & $33.5 \pm 2.9$ & $32.3 \pm 2.3$ & $27.7 \pm 4.6$ \\
\hline $\begin{array}{l}\text { Ventroposterior thalamic nucleus, lateral } \\
\text { part }\end{array}$ & & $26.7 \pm 2.0$ & $27.4 \pm 2.3$ & $26.2 \pm 0.9$ & $21.0 \pm 4.2$ \\
\hline Posterior thalamic nuclear group & & $22.9 \pm 1.6$ & $31.6 \pm 1.2$ & $30.8 \pm 2.0$ & $31.6 \pm 5.3$ \\
\hline Laterodorsal thalamic nucleus & $4.7 \pm 0.4$ & $21.4 \pm 1.9$ & $24.2 \pm 2.3$ & $27.6 \pm 0.5$ & $29.8 \pm 2.8$ \\
\hline Habenular nucleus & & $14.9 \pm 0.6$ & $22.5 \pm 3.5$ & $20.1 \pm 3.2$ & $13.7 \pm 2.2$ \\
\hline \multicolumn{6}{|l|}{ Hypothalamus } \\
\hline Dorsal hypothalamic area & & $9.0 \pm 1.3$ & $11.8 \pm 0.6$ & $18.0 \pm 2.7$ & $15.3 \pm 0.4$ \\
\hline Ventromedial hypothalamic nucleus & $4.7 \pm 2.0$ & $11.1 \pm 0.8$ & $11.7 \pm 0.8$ & $16.3 \pm 0.7$ & $9.7 \pm 2.2$ \\
\hline Lateral hypothalamic area & $4.0 \pm 0.8$ & $17.2 \pm 5.1$ & $15.6 \pm 0.7$ & $19.6 \pm 3.1$ & $10.6 \pm 2.2$ \\
\hline \multicolumn{6}{|l|}{ Midbrain } \\
\hline Substantia nigra, reticular part & $7.3 \pm 1.5$ & $29.9 \pm 3.4$ & $44.1 \pm 12.1$ & $53.0 \pm 2.0$ & $50.1 \pm 3.4$ \\
\hline Medial geniculate nucleus & $6.3 \pm 1.3$ & $27.0 \pm 5.2$ & $26.2 \pm 2.8$ & $26.6 \pm 4.8$ & $21.2 \pm 3.9$ \\
\hline Superficial gray layer of superior colliculus & & $16.4 \pm 0.3$ & $18.0 \pm 7.5$ & $20.3 \pm 3.5$ & $18.0 \pm 2.7$ \\
\hline Anterior pretectal area & & $13.8 \pm 0.9$ & $21.4 \pm 5.1$ & $20.4 \pm 2.8$ & $11.2 \pm 2.0$ \\
\hline Central gray & $6.2 \pm 1.3$ & $10.1 \pm 2.1$ & $18.9 \pm 7.4$ & $21.5 \pm 3.1$ & $16.7 \pm 2.0$ \\
\hline Red nucleus & & $13.1 \pm 0.7$ & $17.9 \pm 1.6$ & $20.0 \pm 2.4$ & $7.8 \pm 0.8$ \\
\hline Inferior colliculus & & & & $34.2 \pm 1.6$ & $20.3 \pm 1.0$ \\
\hline \multicolumn{6}{|l|}{ Pons } \\
\hline Facial nucleus & & $25.7 \pm 1.1$ & $22.9 \pm 2.8$ & $21.0 \pm 2.5$ & $20.7 \pm 4.1$ \\
\hline Dorsal tegment nucleus & $6.4 \pm 0.7$ & $14.8 \pm 0.6$ & $17.6 \pm 2.3$ & $23.6 \pm 2.3$ & $14.7 \pm 6.4$ \\
\hline Ventral parabrachial nucleus & & $11.7 \pm 0.4$ & $13.9 \pm 2.2$ & $21.2 \pm 4.9$ & $11.3 \pm 2.4$ \\
\hline Pontine reticular nucleus, caudal part & $6.7 \pm 1.5$ & $15.5 \pm 0.6$ & $13.6 \pm 2.7$ & $18.6 \pm 1.9$ & $6.9 \pm 1.1$ \\
\hline Motor trigeminal nucleus & & $25.2 \pm 1.3$ & $20.0 \pm 2.8$ & $20.1 \pm 5.8$ & $9.7 \pm 2.6$ \\
\hline Raphe pontis nucleus & & $14.5 \pm 1.0$ & $13.3 \pm 0.9$ & $20.1 \pm 1.3$ & $9.6 \pm 0.4$ \\
\hline \multicolumn{6}{|l|}{ Medulla } \\
\hline Hypoglossal nucleus & $7.3 \pm 1.4$ & $26.9 \pm 1.3$ & $35.0 \pm 8.9$ & $32.6 \pm 1.3$ & $25.5 \pm 1.2$ \\
\hline External cuneate nucleus & & $25.2 \pm 5.7$ & $20.4 \pm 0.4$ & $21.9 \pm 3.7$ & $15.9 \pm 2.0$ \\
\hline Cuneate nucleus & & $15.5 \pm 0.7$ & $15.7 \pm 0.8$ & $17.4 \pm 2.6$ & $10.9 \pm 1.3$ \\
\hline Raphe obscurus nucleus & & $18.2 \pm 2.1$ & $11.7 \pm 0.3$ & $9.9 \pm 2.0$ & $5.8 \pm 1.5$ \\
\hline Medullary reticular nucleus & $7.7 \pm 1.3$ & $17.0 \pm 0.9$ & $15.8 \pm 0.4$ & $16.1 \pm 3.6$ & $8.6 \pm 0.4$ \\
\hline Inferior olive & & $19.0 \pm 5.5$ & $23.0 \pm 5.4$ & $16.1 \pm 1.5$ & $11.6 \pm 2.4$ \\
\hline Spinal trigeminal nucleus, caudal part & $8.6 \pm 0.4$ & $18.9 \pm 0.4$ & $17.5 \pm 1.1$ & $18.8 \pm 2.4$ & $8.9 \pm 0.8$ \\
\hline \multicolumn{6}{|l|}{ Cerebellum } \\
\hline Cerebellum, granular layer & $2.3 \pm 0.3$ & $14.3 \pm 1.1$ & $19.9 \pm 5.9$ & $20.3 \pm 4.4$ & $20.7 \pm 1.0$ \\
\hline Cerebellum, molecular layer & $2.5 \pm 0.3$ & $24.6 \pm 2.2$ & $31.7 \pm 6.9$ & $35.8 \pm 1.8$ & $42.5 \pm 2.7$ \\
\hline
\end{tabular}

* Unit $=\mathrm{fmol} / \mathrm{mg}$ tissue.

the $O D$ values were converted to binding density of labeled glibenclamide. The measurements from bilateral areas in a section were averaged as a single value. Three corresponding sections were analyzed for one area per animal. The binding density value of a nucleus, in $\mathrm{fmol} / \mathrm{mg}$ tissue, was expressed as mean $\pm \mathrm{SD}$ from 12 sections of four animals in each group. In some regions, data from several nuclei examined were averaged as a single value to reflect general density.

\section{RESULTS}

Ontogeny of Sulfonylurea Receptors in Rat Brain. Table 1 and Figure 2 show the quantitation of sulfonylurea receptor density in the CNS from birth to adulthood.

Very low density throughout CNS at birth. As seen in Table 1 and Figures 2 and 3, there was a comparatively low density of 

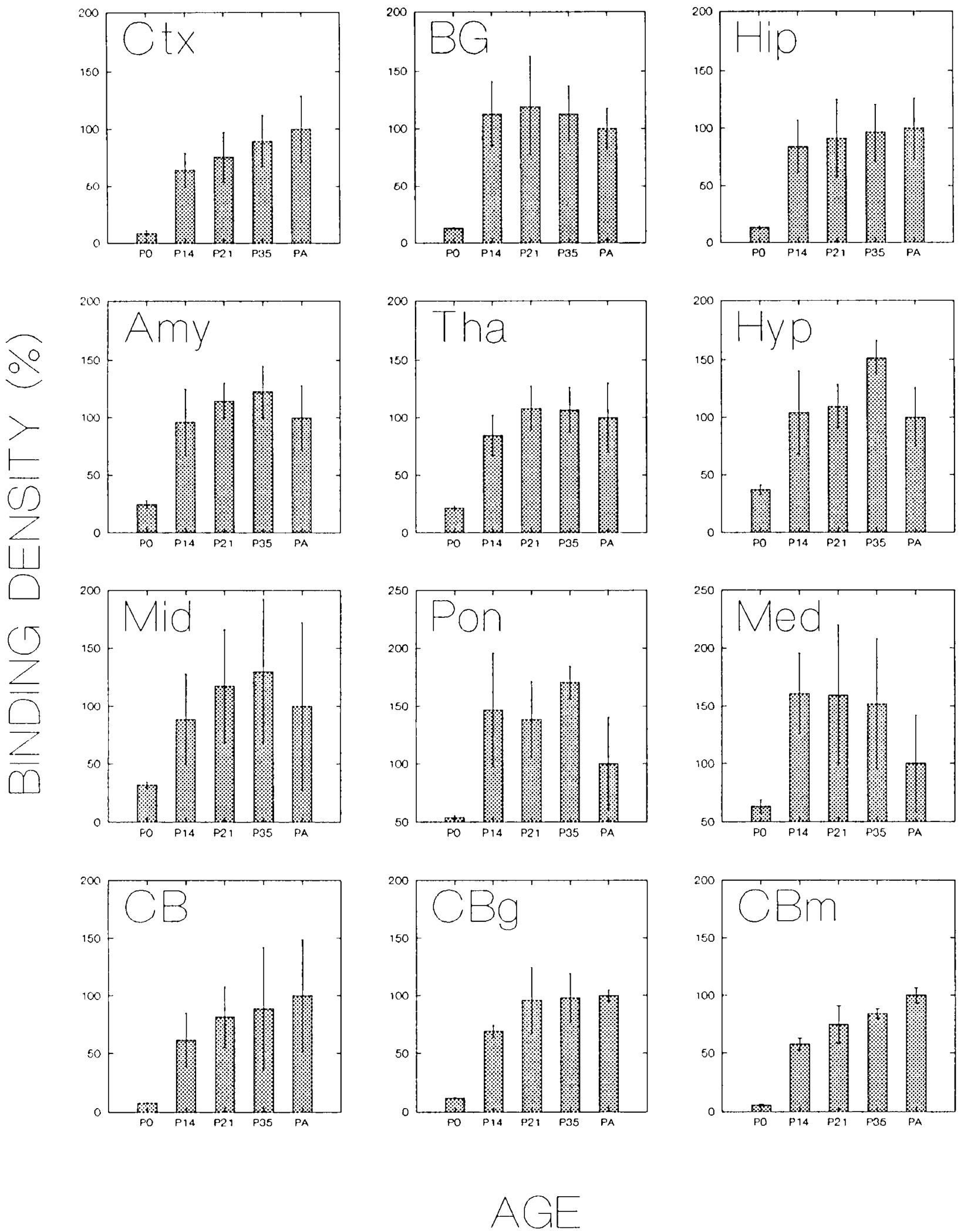

Fig. 2. Development of sulfonylurea receptors in major brain regions. Note that SD reflects differences among nuclei in regions. $A m y$; amygdaloid; $B G$, basal ganglia: $C B$, cerebellum; $C B g$, granular layer of cerebellum; $C B m$, molecular layer of cerebellum; $C t x$, frontal cortex; $/ I i p$, hippocampus: Hyp, hypothalamus; Med, medulla: Mfid, midbrain: and Tha, thalamus.

glibenclamide binding sites at birth throughout the rat CNS with an extremely low density in the cerebellum and the cortex. The brainstem, midbrain, and some thalamic nuclei (e.g. ventroposterior and ventrolateral nuclei) had a higher binding density than other regions, but the density levels were still lower than those in the adult (Fig. 1).
Fast development and sulfonylurea receptor expression in the first 2 wh afier birth. Binding sites developed relatively quickly during the first 2 wks. By P14, most brainstem nuclei had reached peak levels. In the cerebellum and rostral brains. the density increased by several to more than 10 -fold. Receptor expression was, however, very heterogeneous. For example, the globus pal- 


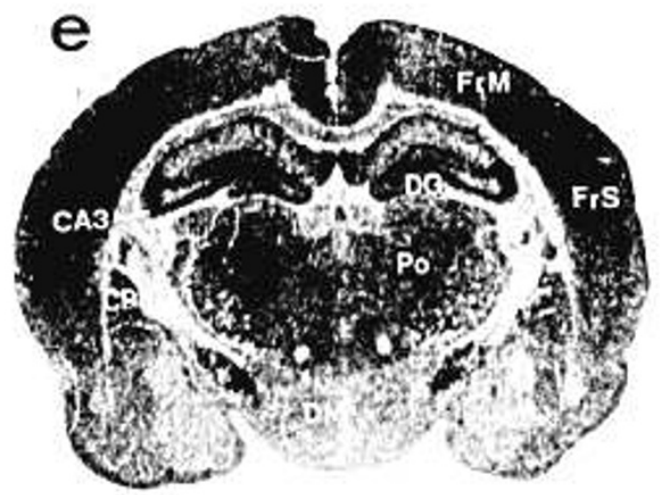

b
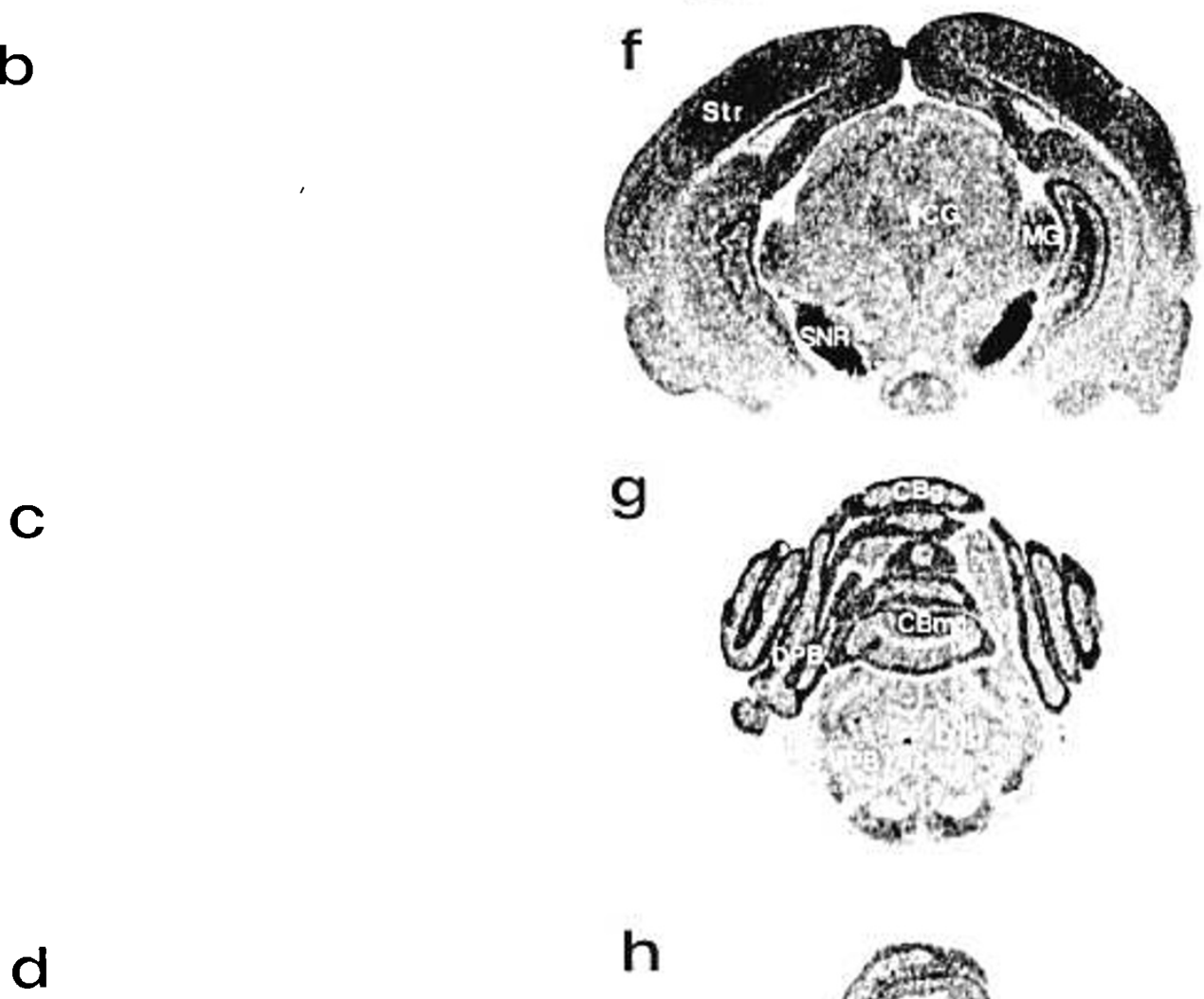

h

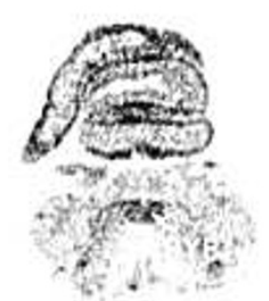

Fig. 3. Comparison of sulfonylurea receptor density between P0 and P35. Note that the binding density in the newborn is homogeneous and extremely low and that the distribution pattern in P35 is very similar to that of the adult (Fig. 1). The density scales in this figure are different from those in other figures. $a-d$. rostral to caudal brain levels in the newborn rat (P0): $e-h$, rostral to caudal brain levels in the P35 rat. See legend of Figure 1 for abbreviations.

lidus had a density as high as $38 \mathrm{fmol} / \mathrm{mg}$ tissue. The CA 3 area of hippocampus, substantia nigra, caudate putamen, thalamic nuclei, and hypoglossal nucleus also had high binding density (more than $20 \mathrm{fmol} / \mathrm{mg}$ tissue) at this stage. But the central gray and dorsal hypothalamic areas had a density of $9-10 \mathrm{fmol} / \mathrm{mg}$ tissue.

Slower development during subsequent postnatal weeks. Sulfonylurea receptor density changed at a slow rate in the $3 \mathrm{rd} \mathrm{wk}$ postnatally (Table 1). In the brainstem, most nuclei had no or little change in binding density compared with the P14 levels: only a few nuclei such as the hypoglossal nucleus increased in receptor density. In rostral brain areas, the rate of expression during this period varied. Most areas such as the motor area of the frontoparietal cortex, the auditory area of the temporal cortex, and hippocampus increased receptor density but at a much lower rate compared with the first $2 \mathrm{wk}$ of life. In contrast, the somatosensory area of the frontopariel cortex, striate cortex, and both the molecular and granular layers of the cerebellum continued to increase at a fast rate.

Most brain areas, both brainstem and rostral areas, had little change in receptor density between P21 and P35 (Table 1). For example, the densities of the ventroposterior thalamic nucleus and posterior thalamic nuclear group at P35 were 32 and 31 $\mathrm{fmol} / \mathrm{mg}$ tissue, respectively, which were very similar to levels at P21.

Sulfonylurea receptor densities at P21 or P35 represented peak 

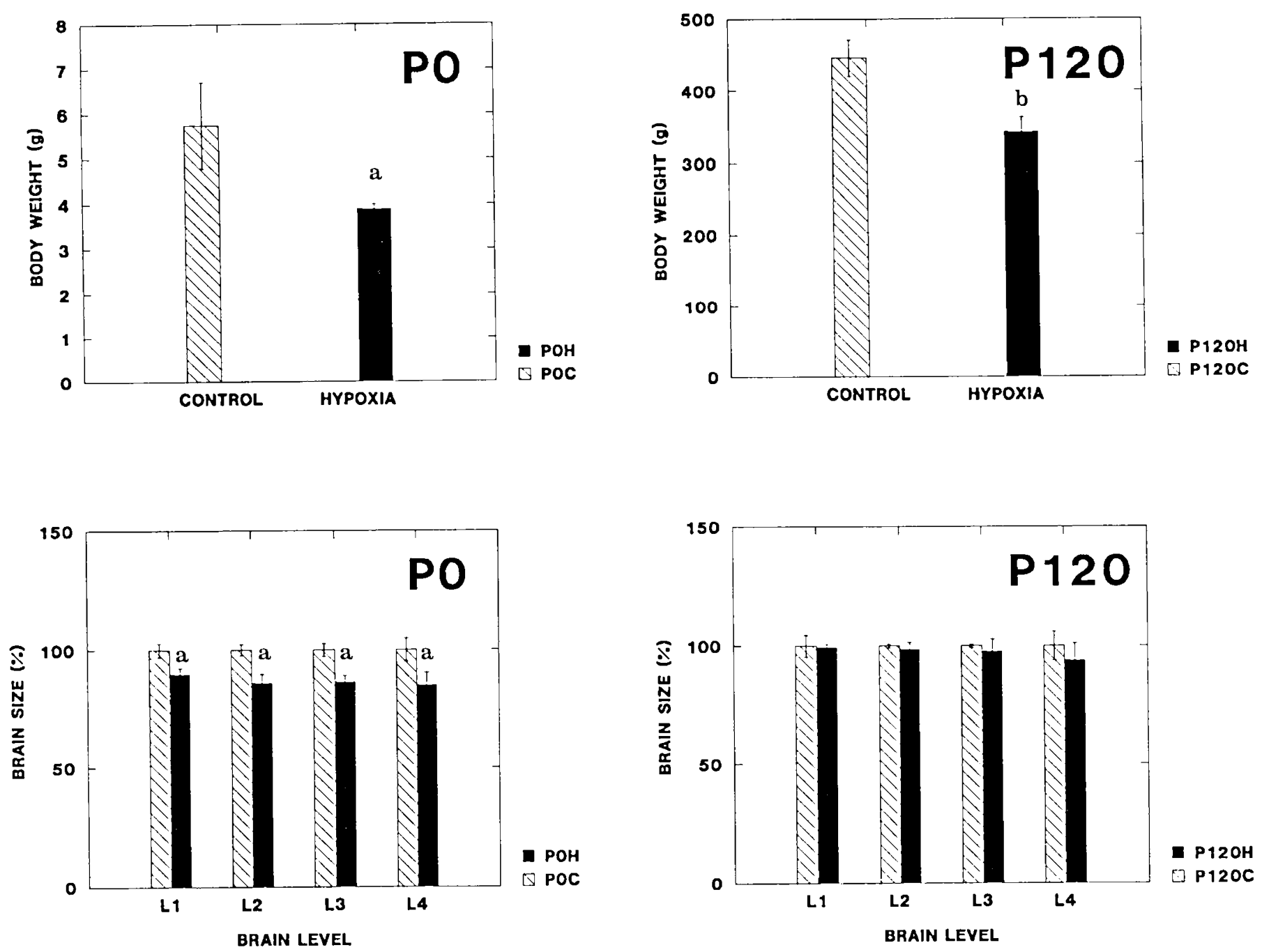

Fig. 4. Effect of chronic hypoxia on body weight and brain size. The values of body weight are derived from four to six animals per group. and those of brain size from nine to 12 sections in each group. Note that there is a large decrease in body weight of both hypoxia groups and a major decrease in brain size in POH. $a, p<0.05 ; b, p<0.01$.

Table 2. Comparison of ${ }^{3} H$-glibenclamide binding activity in control rats and rats exposed to hypoxia in utero*

\begin{tabular}{ccc}
\hline Brain level & \multicolumn{1}{c}{ Control } & \multicolumn{1}{c}{ Hypoxia } \\
\hline L1 & $19.0 \pm 8.6$ & $39.6 \pm 16.1$ \\
L2 & $21.3 \pm 4.9$ & $96.4 \pm 33.3 \dagger$ \\
L3 & $18.8 \pm 5.0$ & $99.5 \pm 21.9 \dagger$ \\
L4 & $73.7 \pm 24.6$ & $81.1 \pm 31.5$ \\
\hline
\end{tabular}

* Value unit: $\mathrm{fmol} / \mathrm{mg}$ protein.

$+p<0.05$.

levels for most brain areas (Table 1, Fig. 3). After P35, most subcortical areas including the thalamus, hypothalamus, and midbrain decreased in density by a small amount and reached adult levels. In the hippocampus, substantia nigra, facial nucleus, and granular layer of the cercbellum, there was no difference in the receptor density between $\mathrm{P} 35$ and $\mathrm{P} 120$. In almost all brainstem areas, however, binding density decreased by a measurable amount. For example, the pontine and medullary reticular nuclei decreased in density by $45-60 \%$, while most cortical areas and the molecular layer of the cerebellum kept increasing in receptor density during this period. As seen in Figure 2, the density of the cortex was higher at P120 than in P35.

Sulfonylurea Receptor Expression during Chronic Hypoxia. Chronic hypoxia greatly affected rat development in utero. As shown in Figure 4, hypoxia caused a decrease not only in body weight but also in brain size. The amount of brain protein in $\mathrm{P} 0 \mathrm{H}$ decreased by $10-15 \%$ in most brain levels. In the adult rat, however, hypoxia did not affect brain size (Fig. 4) significantly, although body weight decreased greatly. Data of the brain weight showed that weight of hypoxic rat brains $(2.03 \pm 0.07 \mathrm{~g}$, mean $\pm \mathrm{SD}, n=4)$ was very close to control level $(2.15 \pm 0.04 \mathrm{~g}$. mean $\pm \mathrm{SD}, n=4)$. The brain protein declined by less than $8 \%$ in all brain levels. The most striking difference between ages was in hematocrit, which decreased by about $40 \%$ in $\mathrm{POH}$ (from 45.8 \pm 3.3 in the control to $27.5 \pm 2.1$ in hypoxia, mean $\pm \mathrm{SD}, n=$ 4) but increased by about $50 \%$ in the adult hypoxic rats (from $42.0 \pm 1.8$ in the control to $62.8 \pm 1.8$ in hypoxia, mean $\pm S D$. $n=4)$.

Our receptor binding data indicated that bound ${ }^{3} \mathrm{H}$-glibenclamide in the hypoxic brain was more than that in control at the same levels (Table 2). Autoradiographic images showed that the hypoxia-induced increase occurred mostly in the rostral brain areas such as the basal ganglia, hippocampus, and thalamus. For example, binding density in the ventroposterior thalamic nucleus was more than $35 \%$ higher in hypoxic pups than in control pups. Midbrain areas such as the central gray matter also had higher binding density in the hypoxic than in the control group. In the brainstem, especially in the medullary areas, there was little or no increase in receptor density with hypoxia. In three major medullary structures (the caudal nucleus of the spinal tract of the trigeminal nerve, the medullary reticular formation, and the 

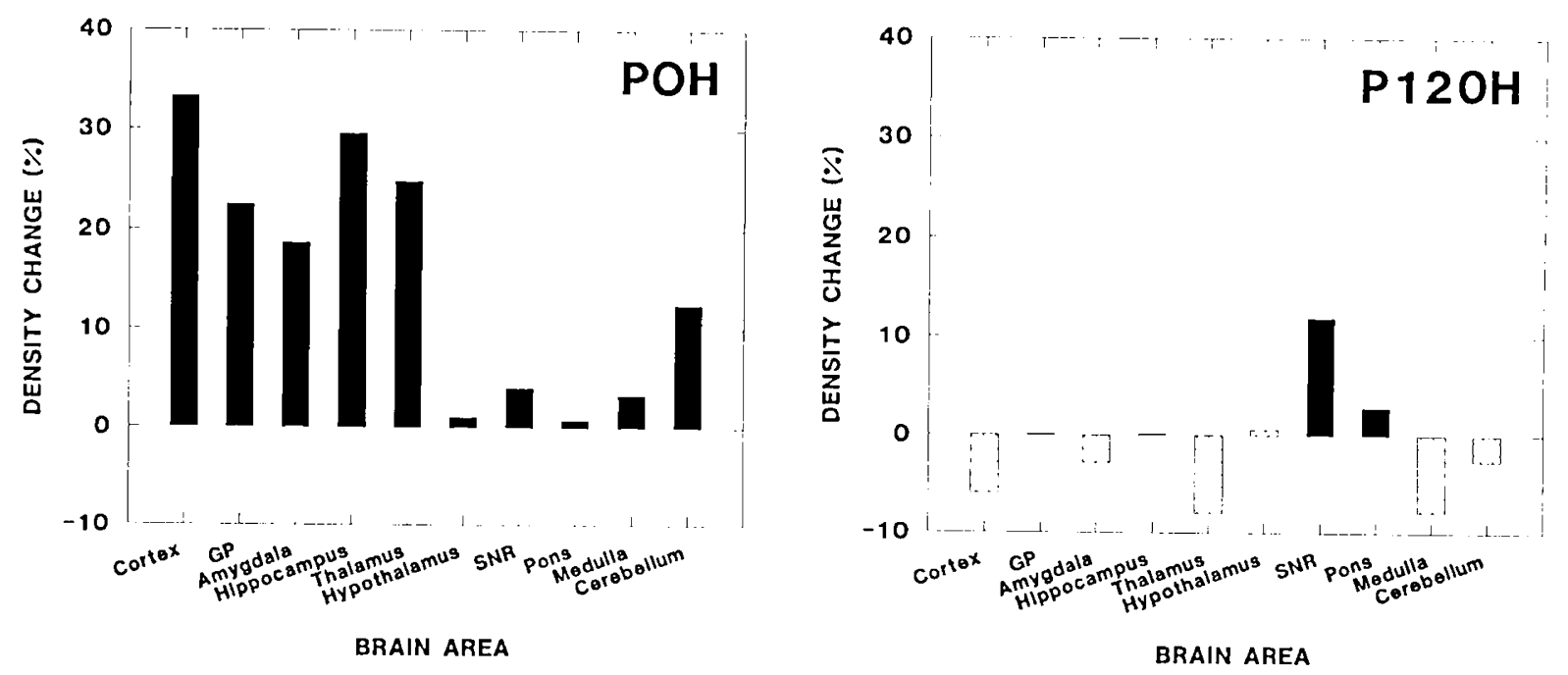

Fig. 5. Effect of chronic hypoxia on ${ }^{3} \mathrm{H}$-glibenclamide binding in major brain regions. The values shown as hars are mean values $(n=4$, either hypoxic or control group) from several nuclei in any given brain region. (FP. globus pallidus; $S N R$, substantia nigra, reticular part. Note that the increase in binding density in rostral areas of newborn pups exposed to hypoxia in utero $(P O I I)$ is not seen in the adult hypoxic rats $(P I 2() I I)$.

hypoglossal nucleus), the average difference in binding density was less than $4 \%$ between hypoxia and control. There was, however, no major decrease in expression in any area studied in newborn rats exposed to hypoxia in utero.

In contrast to $\mathrm{POH}$, there was little change after chronic hypoxia in the adult hypoxic rats. In most areas, glibenclamide binding density in the hypoxic group was close to the control level. Slight decreases (mostly around 10\%) were seen in a few areas such as the entorhinal cortex, basolateral amygdaloid nucleus, posterior thalamic nuclear group, and inferior olive. In the substantia nigra, there was only a slight increase in binding density (Fig. 5).

\section{DISCUSSION}

Ontogeny of sulfonylurea receptors. The present study draws a detailed time course for the postnatal development of sulfonylurea receptors in various areas of the rat CNS. Our results show that sulfonylurea receptor density is very low and its distribution is homogeneous at birth. The large increase in the binding density after birth is due to an increase in receptor number rather than an increase in binding affinity because the $k_{d}$ values for glibenclamide binding in the newborn CNS are very similar to those in the adult (13).

The current results with respect to ontogenic expression are not similar to those of Mourre et al. (14). inasmuch as we observed different developmental profiles. We found a rapid development in the first $2 \mathrm{wk}$ after birth. For example, by P14, most rostral brain areas had a density that was larger than $50 \%$ of the adult level. Mourre et al. (14) observed a much slower developing profile than what we demonstrated. By $15 \mathrm{~d}$, the motor area of the frontoparietal cortex in their rats contained a density of only about $30 \%$ of the adult levels. In addition, we found that in almost all brain areas there was no major increase in density after P35, but Mourre et al. showed that many areas increased in density by a large amount after P32. Possible reasons that could explain the differences between our study and theirs are related to rat species (Sprague-Dawley versus Wistar) and adult age used (P120 versus P90).

Although we provide strong evidence that an increase in glibenclamide binding density or receptor number occurs with postnatal age, the implications of this increase may not be straightforward. The function of these receptors has been invoked at a number of CNS sites and in a number of physiologic and pathophysiologic conditions such as in glucose metabolism, neurotransmitter release, and seizure disorder and during hypoxic stress $(4,8-10)$. However, we believe that the increase in this receptor with age in various CNS regions supports the idea that this glibenclamide binding site may play a more prominent role in the adult rat brain than in the newborn rat brain. Indeed, we and others have previously shown that this receptor/channel complex plays an important role during $\mathrm{O}_{2}$ deprivation in the adult rat. Mature neurons activate the efflux of $\mathrm{K}^{+}$through these channels when ATP decreases to a low level $(4,10,15)$. Such receptors are not well developed in early life, possibly because the level of ATP or high-energy phosphate groups does not decrease as readily during stress in the newborn as in the adult or mature nerve cell (15). Although the relation between sulfonylurea receptors and $\mathrm{K}^{+}$efflux during hypoxia in the CNS is based on a number of studies $(4,6-8,14,16,17)$, there are newer studies showing that glibenclamide may not be a specific blocker for $K_{\text {ATP }}$ channels $(18,19)$. Therefore, we caution the reader that there may be other $\mathrm{K}^{+}$channels that are contributing to $\mathrm{K}^{+}$ efflux during hypoxia.

Chronic hypoxia and sulfonylurea receptors. Although effect of transient ischemia on brain glibenclamide binding sites has been reported (16), there is no information about the sulfonylurea receptor regulation during chronic hypoxia with development. Our results showed that the effect of in utero chronic hypoxia on binding sites is clearly different from that of the adult. Although there is a consistent increase in the receptor density in practically all rostral CNS areas studied in $\mathrm{P} 0 \mathrm{H}$, there is no increase or even decrease in most adult brain areas in response to hypoxia. There are several important issues that should be addressed in this regard.

First, although $\mathrm{PO}_{2}$ measurements in brain tissue would have been very helpful in ascertaining a drop in $\mathrm{O}_{2}$ with the inhalation of a lower $\mathrm{FiO}_{2}$, these measurements are very difficult to perform. especially on fetuses in utero or in the very young. It is reassuring, however, that the effect of hypoxia is detected on variables other than glibenclamide receptor density. For example, the hematocrit was altered and body and brain size were decreased. In addition, total brain protein was diminished. A corollary issue is whether the fetal and adult brains were exposed to similar hypoxic conditions. This is an important question that cannot be easily addressed without actual $\mathrm{PO}_{2}$ and other physiologic measurements. However, our experiments have been performed to determine the effect of chronic hypoxia at each age and not necessarily compare across ages. In addition, chronic exposure of rats to a level lower than an $\mathrm{FiO}_{2}$ of $8 \%$ (a concentration given to rats in this study) may interfere with cardiovascular stability and may jeopardize the model. It is important to realize that the 
observed changes in the present study could have been very different if the duration or severity of hypoxia were altered.

Second. it was relatively clear from our results that receptor expression was higher in the newborn brain after maternal exposure to hypoxia than in control brains, mostly in rostral areas. Indeed, one important aspect of our results is that hypoxia does not have a homogeneous effect in terms of receptor expression on all brain areas.

Third, it is interesting to note that sulfonylurea receptor expression increased in $\mathrm{POH}$ while total brain protein decreased after exposure to chronic hypoxia. Although it may not be appropriate to compare the changes in receptor expression seen in certain specific brain regions with the amount of protein measured in much larger brain areas, our protein assays as well as those of others have always indicated either no change or a distinct decrease in brain protein amount (15). Therefore, one conclusion that can be drawn from these results is that the decrease in cellular protein during $\mathrm{O}_{2}$ deprivation is not generalized. This idea is supported by the fact that some protein such as heat shock protein increased during ischemia in the CNS $(17,20-22)$ at a time when total protein synthesis is diminished. We do not know, however, at what level the hypoxia-induced change occurs, although there is evidence to suggest that hypoxia can affect processes at the transcriptional and translational levels (15).

It is important to note that there was a major difference between immature and adult brain response to hypoxia in our animals, $i . e$., there was no increase in sulfonylurea receptors at the time when there was a decrease in total brain proteins in the adult. In another animal model, Mourre $' t$ al. (16) found that transient ischemia caused no change or a decrease in glibenclamide binding density in adult rat brain. Therefore, our results from hypoxic adult brains are similar to theirs. It is possible that, unlike the immature brain. the adult one does not exhibit the ability to differentially process proteins during hypoxic/ischemic stress, and this may play a key role in hypoxic tolerance.

Acknowledgme'nt. The authors thank Ralph E. Garcia for his technical assistance.

\section{REFERENCES}

1. Cummins TR. Jiang C. Haddad GG 1993 Human neocortical excitability is decreased during anoxia via $\mathrm{Na}^{+}$channel modulation. J Clin Invest 91:608615

2. Donnelly DF, Jiang C. Haddad GG 1992 Comparative responses of brainstem and hippocampal neurons to $\mathrm{O}_{2}$ deprivation: in vitro intracellular studies. Am J Physiol 262:L549-L554

3. Haddad GG. Donnelly DF $1990 \mathrm{O}_{2}$ deprivation induces a major depolarization in brain stem neurons in the adult but not in the neonatal rat. J Physiol (Lond) 429:411-428

4. Jiang C. Xia Y, Haddad GG 1992 Role of ATP-sensitive $K^{+}$channcls during anoxia: major differences between rat (newborn and adult) and turtle neurons. J Physiol (Lond) 448:599-612

5. Jiang C. Haddad GG 1993 Differential response of neocortical neurons to glucose and/or $\mathrm{O}_{2}$ deprivation in the human and rat. J Neurophysiol 68:2165-2173

6. Asheroft SJH. Asheroft FM 1990 Properties and functions of ATP-sensitive K-channels. Cell Signal 2:197-214

7. Bernardi H, Fosset M. Lazdunski M 1988 Characterization, purification. and affinity labeling of the brain $\left[{ }^{3} \mathrm{H}\right] \mathrm{glibenclamide}$-binding protein, a putative neuronal ATP-regulated $\mathrm{K}^{+}$channel. Proc Natl Acad Sci USA 85:98169820

8. Ben-Ari Y 1989 Eiffect of glibenclamide, a sensitive blocker of an ATP-K channel, on the anoxic response of hippocampal neurons. Pflugers Arch 414:S111-S114

9. Mourre C, Ben-Ari Y', Bernardi H, Fosset M, Lazdunski M1 1989 Antidiabetic sulfonylurea: localization of binding sites in the brain and effects on the hyperpolarization induced by anoxia in hippocampal slices. Brain Res $486: 159-164$

10. Xia Y. Jiang C, Haddad GG 1992 Oxidative and glycolytic pathways in rat (newborn and adult) and turte brain: role during anoxia. Am J Physiol 262:R595-R603

11. Paxinos G. Watson C 1982 The Rat Brain in Stereotaxic Coordinates. Academic Press. New York

12. Bradford MM $1976 \mathrm{~A}$ rapid and sensitive method for the quantitative of microgram quantities of protein utilizing the principle of protein-dve hinding. Anal Biochem 72:248-254

13. Xia Y. Haddad GG 1991 Major differences in CNS sulfonylurea receptors between rat (newborn and adult) and turtle. J Comp Neurol 314:278-289

14. Mourre C. Widmann C. Lazdunski M 1990 Sulfonvlurea binding sites associated with ATP-regulated $\mathrm{K}^{+}$channels in the central nervous system: autoradiographic analysis of their distribution and ontogenesis. and of their localization in mutant mice cerchellum. Brain Res 519:29-43

15. Haddad $\mathrm{GG}$, Jiang $\mathrm{C} 1993 \mathrm{O}_{2}$ deprivation in the central nervous system: on mechanisms of neuronal response, differential sensitivity and injury. Prog Neurobiol 40:277-318

16. Mourre C. Smith ML. Siesjo BK, I azdunski M 1990 Brain ischemia alters the density of binding sites for glitunclamide, a specific blocker of ATP-sensitive $\mathrm{K}^{+}$channels. Brain Res 526:147-152

17. Nowak Jr TS 1991 Localization of $70 \mathrm{kDa}$ stress protein mRNA induction in gerbil brain after ischemia. J Cereb Blood Flow Metab 11:432-4.39

18. Cripel V. Krnjevic K. Ben-Ari Y 1992 Glibenclamide depresses the slowly inactivating outward current $\left(I_{D}\right)$ in hippocampal neurons. Can J Physiol Pharmacol 70:306-307

19. Reeve HL. Vaughan PFT, Peers C 1992 Glibenclamide inhibits voltage-gated $\mathrm{K}^{+}$current in the human neuroblastoma cell line SHI-SY'5Y'. Neuro Let 135:37-40

20. Abe K. Tanzi RE, Kogure $\mathrm{K} 1991$ Induction of HSP70 mRNA after transient ischemia in gerbil brain. Neurosci Lett 29:166-168

21. Brown IR 1990 Induction of heat shock (stress) genes in the mammalian brain by hyperthermia and other traumatic events: a current perspective. J Neu rosci Res 27:247-255

22. Gonzalez MF, Lowenstein D, Fernyak S, Hisanaga K, Simon R, Sharp F 1990 Induction of heat shock protein 72-like immunoreactivity in the hippocampal formation following transient global ischemia. Brain Res Bull 26 . 241-250 